\title{
Structural characterization of bulk and nanoparticle lead halide perovskite thin films by (S)TEM techniques
}

N. Fernández-Delgado ${ }^{1 *}$, M. Herrera ${ }^{1}$, F. J. Delgado ${ }^{1}$, A. H. Tavabi², M. Luysberg², R. E. DuninBorkowski², E. J. Juárez-Pérez ${ }^{3}$, B. C. Hames ${ }^{3}$, I. Mora-Sero ${ }^{3}$, I. Suárez ${ }^{4}$, J. P. Martínez-Pastor ${ }^{4}$, S. I. Molina ${ }^{1}$

$1 *$ Department of Material Science, Metallurgical Engineering and Inorganic Chemistry IMEYMAT, University of Cadiz, Spain, natalia.fernandezdelgado@uca.es

${ }^{2}$ Ernst Ruska-Centre for Microscopy and Spectroscopy with Electrons and Peter Grünberg Institute, Forschungszentrum Jülich, Germany

${ }^{3}$ Institute of Advanced Materials (INAM), University of Jaume I, Spain

${ }^{4}$ Research Institute of Materials Science, University of Valencia, Spain

\section{Abstract}

In the last few years, lead halide $\left(\mathrm{APbX}_{3}\right)$ perovskites, which are of interest for applications in photovoltaic and photonic devices, have demonstrated excellent optoelectronic performance. The structural characterization of $\mathrm{APbX}_{3}$ thin films using (scanning) transmission electron microscopy ((S)TEM) techniques can provide valuable information that can be used to understand their optoelectronic performance and device properties. However, since $\mathrm{APbX}_{3}$ perovskites are soft materials, their characterization using (S)TEM is challenging. Here, we study two $\mathrm{APbX}_{3}$ perovskite thin films: bulk $\mathrm{CH}_{3} \mathrm{NH}_{3} \mathrm{Pbl}_{3}$, and nanoparticle (NP) $\mathrm{CsPbBr}_{3}$. Both specimen preparation methods and working conditions for analysis by (S)TEM are optimized. On the one hand, we show that $\mathrm{CH}_{3} \mathrm{NH}_{3} \mathrm{Pbl}_{3}$ thin films grown by a one step method are composed of independent grains with random orientations. The growth method results in the formation of tetragonal perovskite films with good adherence to an underlying $\mathrm{TiO}_{2}$ layer and with a photoluminescence (PL) emission band that has a Gaussian shape and is centered at $775 \mathrm{~nm}$. On the other hand, in the NP CsPbBr 3 perovskite thin films the colloidal NPs, which are used as the building blocks of the film, are preserved by the deposition process. Small gaps are observed between adjacent NPs in the deposited film. The crystal structure is cubic, which is beneficial due its optimal band gap. The colloidal NPs shows similar absorption and PL in the thin film as in the colloidal solution, indicating good homogeneity and the absence of aggregation of NPs in the film. Care was required to avoid long electron irradiation times during these studies, even at a low voltage of $80 \mathrm{kV}$, as the material was observed to decompose through $\mathrm{Pb}$ segregation.

\section{Introduction}

Lead halide $\left(\mathrm{APbX}_{3}\right)$ perovskites are highly promising materials for use in photovoltaic and optoelectronic applications [1] because of their high photo-conversion efficiencies (up to $22.7 \%$ ), excellent light emission properties [2], and low cost fabrication [1]. Their outstanding properties include high absorption coefficients and sharp absorption edges [3], bandgaps that are tunable with composition, and high emission quantum yields at room temperature. Hybrid $\mathrm{CH}_{3} \mathrm{NH}_{3} \mathrm{Pbl}_{3}$ has attracted particular attention, as it is the first halide perovskite used in photovoltaic applications [3,4]. $\mathrm{CH}_{3} \mathrm{NH}_{3} \mathrm{Pbl}_{3}$ thin films have direct bandgaps of $\sim 1.6 \mathrm{eV}$ and high carrier mobilities, resulting in solar cells with conversion efficiencies of up to $22.7 \%$ [6], and optical amplifiers with low thresholds of stimulated emission [7]. However, $\mathrm{CH}_{3} \mathrm{NH}_{3} \mathrm{Pbl}_{3}$ films degrade under ambient conditions, especially in the presence of moisture $[8,9]$. In contrast, inorganic perovskites have demonstrated higher stability $[10,11]$. In particular, $\mathrm{CsPbBr}_{3}$ nanocrystals have been shown to exhibit $\sim 90 \%$ PL efficiency with a narrow full width at half maximum (FWHM) $[12,13]$ and have a highly emissive crystal phase that is stable at room 
temperature [14], leading to enormous potential for applications in optoelectronic devices. Examples of inorganic perovskite-based devices are light emitting diodes [15], photodetectors [16] and solar cells [17]. Although both bulk and nanoparticle thin films have similar perovskite lattices, they have different structural properties that need to be understood to optimize their optoelectronic properties and to integrate them efficiently in solid state devices. Control of their structural properties, such as crystallinity [18] and composition [19], is a key issue for device efficiency. Crystalline defects and grain boundaries can act as non-radiative recombination sites that affect photovoltaic properties [20,21]. Parameters such as film roughness and surface coverage after deposition of the material on a substrate also need to be controlled to obtain smooth and continuous layers in high-efficiency solar cells [22,23]. Other issues include the longterm stability of the active layer. A poly (methyl methacrylate) (PMMA) film deposited on the perovskite layer has provided the desired stability, as well as benefiting propagation of the excitation beam along the semiconductor [7]. Detailed information about the structural properties of the material after deposition on a substrate is therefore essential. However, only indirect measurements are typically used. For example, the defect density in $\mathrm{CH}_{3} \mathrm{NH}_{3} \mathrm{Pbl}_{3}$ perovskites has been quantified using first-principles calculations and spectroscopic measurements [24]. Direct measurements of the structural properties of $\mathrm{APbX}_{3}$ perovskites are required to understand and improve synthesis and deposition processes. Transmission electron microscopy (TEM) and scanning TEM (STEM) are powerful techniques for the local microstructural characterization of advanced materials [25,26]. Crystalline structure [27] and iodide migration [28] have been studied in $\mathrm{CH}_{3} \mathrm{NH}_{3} \mathrm{Pbl}_{3}$ perovskites using these techniques. Furthermore, they have been used to identify new phases, such as $\mathrm{CsPb}_{2} \mathrm{Br}_{5}$ during the synthesis of $\mathrm{CsPbBr}_{3}$ [29]. Although these studies demonstrate the benefit of (S)TEM techniques for the development of advanced perovskite materials, the characterization of halide perovskites presents particular challenges, as the incident electron beam can degrade the material.

Here, we analyze the structural properties of two different perovskite thin films, comprising bulk $\mathrm{CH}_{3} \mathrm{NH}_{3} \mathrm{Pbl}_{3}$ and $\mathrm{CsPbBr} 3$ NPs, using (S)TEM techniques. Both films were deposited on $\mathrm{SiO}_{2} / \mathrm{TiO}_{2}$ substrates, in order to ensure easy cleavage, and covered by PMMA to enhance their stability to ambient conditions. Specimen preparation and imaging conditions for electron microscopy were optimized to avoid degradation of the materials during the measurements. Special attention was paid to understand the morphologies of the layers and their crystal structures, as these parameters affect the functionalities of potential devices.

\section{Materials and methods}

Bulk $\mathrm{CH}_{3} \mathrm{NH}_{3} \mathrm{Pbl}_{3}$ perovskite thin film preparation:

$\mathrm{Si} / \mathrm{SiO}_{2}$ wafers were cleaned sequentially using acetone, ethanol and isopropanol. The wafers were dried using a $\mathrm{N}_{2}$ stream and heated for $1 \mathrm{~min}$ at $100^{\circ} \mathrm{C}$ over a hot plate. A 40-nm-thick layer of $\mathrm{TiO}_{2}$ was deposited on the $\mathrm{Si} / \mathrm{SiO}_{2}$ wafer by spin coating an anhydrous ethanol solution of titanium isopropoxide and heating at $500{ }^{\circ} \mathrm{C}$ for $30 \mathrm{~min}$ in room atmospheric conditions. THe halide perovskite layer was deposited in a glove-box by spin coating $100 \mu \mathrm{L}$ of the perovskite precursor DMF solution of $40 \%$ or $10 \%(\mathrm{w} / \mathrm{w})$ onto the wafer. After deposition, the substrate was kept at room temperature for $15 \mathrm{~min}$ and then heated to $100{ }^{\circ} \mathrm{C}$ for $1 \mathrm{~h}$ in an oven in air. After depositing the perovskite onto the substrate, a solution of PMMA in toluene was spin coated onto the sample and heated at $150^{\circ} \mathrm{C}$.

$\mathrm{CsPbBr}{ }_{3} \mathrm{NP}$ synthesis and sample deposition:

In order to synthesize $\mathrm{CsPbBr}_{3} \mathrm{NPs}, \mathrm{PbBr}_{2}(0.4 \mathrm{mmol})$ and $\mathrm{CsBr}(0.4 \mathrm{mmol})$ were dissolved in DMF $(10 \mathrm{~mL})$. Upon complete dissolution of the precursors, oleic acid $(1.0 \mathrm{~mL})$ and oleylamine $(0.5 \mathrm{~mL})$ were added to stabilize the precursor solution. Then, the precursor solution $(1.0 \mathrm{~mL})$ was added dropwise to toluene $(10 \mathrm{~mL})$ under vigorous stirring. Strong green emission was 
observed immediately after injection [13]. Thin films of $\mathrm{CsPbBr}_{3} \mathrm{NPs}$ were prepared from the colloidal solution using a doctor bleading technique. This deposition method ensures good film homogeneity and avoids agglomeration of the NPs, as we demonstrated previously for colloidal NPs [30].

\section{Characterization:}

Photoluminescence $(\mathrm{PL})$ measurements were performed in backscattering geometry using a continuous wave (CW) excitation laser at $404 \mathrm{~nm}$ under a weak pump fluency of $20 \mathrm{~W} / \mathrm{cm}^{2}$ and collecting the back-emitted PL into an HR4000 Ocean Optics spectrograph.

Absorption was obtained using a Shimadzu UV-2501PC spectrophotometer (UV-visible range), or by measuring the transmittance using a commercial reflectometer (Nanocalc from Micropack).

Electron-transparent specimens of $\mathrm{CH}_{3} \mathrm{NH}_{3} \mathrm{Pbl}_{3}$ were prepared for (S)TEM analysis using two methods. The first method involved conventional grinding, polishing and $\mathrm{Ar}^{+}$ion milling using a precision ion polishing system (PIPS) from Gatan. The second method involved focused ion beam (FIB) milling using a Helios Nanolab 650 DualBeam from FEl Company. The $\mathrm{CsPbBr}_{3}$ specimen was also prepared using FIB milling. (S)TEM measurements were performed using an FEI Titan Themis Cubed TEM and an FEI Titan G2 80-200 ChemiSTEM equipped with a Super-X energy dispersive $X$-ray (EDX) spectrometer. Eje $Z$ software [31] was used for the simulation of digital diffraction patterns (DDPs) of the perovskites. The $\mathrm{CH}_{3} \mathrm{NH}_{3} \mathrm{Pbl}_{3}$ perovskites considered are orthorhombic $(P n m a)$, tetragonal $(14 / \mathrm{mcm})$ and cubic $(P m 3 m)$, while the $\mathrm{CsPbBr}_{3}$ perovskites considered are cubic $(P m-3 m)$, tetragonal $(P 4 / \mathrm{mbm})$ and orthorhombic (Pnma).

\section{Results and discussion}

Fig. 1a shows absorbance and $\mathrm{PL}$ spectra recorded from the $\mathrm{CH}_{3} \mathrm{NH}_{3} \mathrm{Pbl}_{3}$ perovskite film as blue and red lines, respectively. The sharp absorption edge is localized at $750-760 \mathrm{~nm}$, while the exciton absorption peak is centered at $750 \mathrm{~nm}$, in accordance with previous publications [3]. The $\mathrm{PL}$ emission band has a Gaussian shape centered on $775 \mathrm{~nm}$ which is associated with a tetragonal structure [32], and has a FWHM of $46 \mathrm{~nm}$. The absorption of colloidal $\mathrm{CsPbBr}_{3} \mathrm{NPs}$ in this work (solid blue line in Fig. 1b) is associated with a band edge at $\sim 510 \mathrm{~nm}$, with the excitonic peak localized at $501 \mathrm{~nm}$, in agreement with previous results reported for this material [33]. The PL spectrum has a Gaussian shape (green solid line in Fig. 1b), which is centered at $517 \mathrm{~nm}$, is related to the cubic structure [34] and has a FWHM of $21 \mathrm{~nm}$. This red Stokes shift can be explained by aggregation of the NPs [35]. The film of colloidal NPs shows similar absorption and $\mathrm{PL}$ as the colloidal solution (blue and green dashed lines in Fig. 1b, respectively), indicating good homogeneity and the absence of aggregation of NPs in the film.
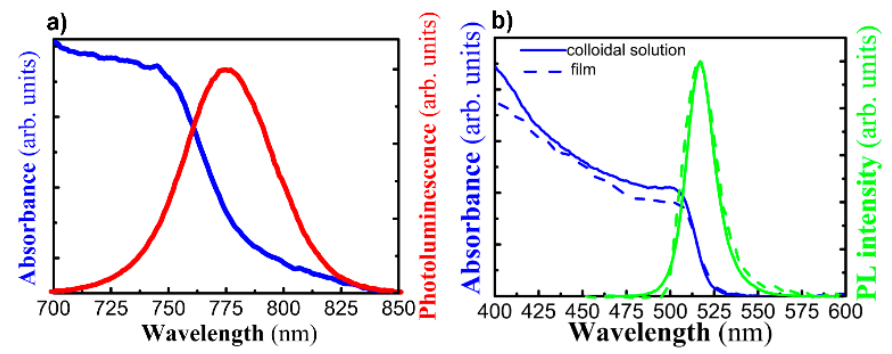

Fig. 1 a) Absorbance and PL spectra recorded from the $\mathrm{CH}_{3} \mathrm{NH}_{3} \mathrm{Pbl}_{3}$ film; b) Absorbance and PL spectra recorded from $\mathrm{CsPbBr}_{3}$ nanoparticles in colloidal solution and a film.

TEM analysis of $\mathrm{CH}_{3} \mathrm{NH}_{3} \mathrm{Pbl}_{3}$ initially focused on the specimen prepared using a conventional method. Fig. 2a shows a TEM image, in which the different layers of the structure can be 
distinguished. In order to study the crystalline quality of the layers, fast Fourier transform (FFT) analysis was carried out. Surprisingly, most of the material formed on the $\mathrm{TiO}_{2}$ layer was found to be non-crystalline, as shown by characteristic amorphous rings in the corresponding FFT (see inset to Fig. 2a). EDX analysis shows that the composition of the amorphous material is consistent with that expected for the perovskite layer, as shown in the second inset to Fig. 2 a. The large amount of amorphous material present suggests that amorphization may have taken place during specimen preparation for TEM. FIB milling was therefore used as an alternative specimen preparation procedure. Fig. $2 \mathrm{~b}$ shows a TEM image of $\mathrm{CH}_{3} \mathrm{NH}_{3} \mathrm{Pbl}_{3}$ prepared using FIB milling, in which the perovskite and $\mathrm{TiO}_{2}$ layers can now be observed. The FFT (shown as an inset) contains spots corresponding to a crystalline structure. A second inset shows a high-resolution TEM (HRTEM) image of $\mathrm{CH}_{3} \mathrm{NH}_{3} \mathrm{Pbl}_{3}$, in which atomic planes can be distinguished, confirming the crystalline nature of the material. The advantage of FIB milling for preparation of halide perovskites for (S)TEM results from the use of $\mathrm{a} \mathrm{Ga}^{+}$ion gun with a well-controlled beam to thin the specimen to electron transparency. The angle of incidence of the $\mathrm{Ga}^{+}$ions is almost parallel to the surface of the material during thinning, whereas in the PIPS used for conventional preparation the $\mathrm{Ar}^{+}$ion beam has an angle of $3.5^{\circ}$. Although the same ion voltage $(\sim 2 \mathrm{kV})$ is used in the last step of the thinning process in both methods, the PIPS is more aggressive than the FIB for the present materials, despite higher voltage used for FIB milling during the intermediate steps of the process.

After optimization of the specimen preparation method, the conditions for TEM analysis need to be considered, including the choice of microscope accelerating voltage. Figs $2 \mathrm{c}$ and $2 \mathrm{~d}$ show two TEM images of the same region of $\mathrm{CH}_{3} \mathrm{NH}_{3} \mathrm{Pbl}_{3}$ before and after analysis at $200 \mathrm{kV}$. The area analyzed (marked with a red rectangle) suffered clear beam damage during TEM examination. Radiolysis and knock-on damage are the two most significant interactions between an incident electron beam and a specimen in the TEM. In general, radiolysis is reduced at higher accelerating voltages, whereas knock-on damage is increased [36]. Damage to the specimen depends on the nature of the material. Radiolysis remains a major limitation when studying certain ceramics and minerals and most polymers [37]. In contrast, knock-on damage usually has a stronger effect on materials such as certain semiconductors and low-Z metals/alloys [37]. Similar materials may behave differently. For example, the threshold energy required to produce a Frenkel defect by knock-on damage is smaller for Ge than for $\mathrm{Si}$ [38]. Our results suggest that the use of a high accelerating voltage is not appropriate for TEM studies of $\mathrm{CH}_{3} \mathrm{NH}_{3} \mathrm{Pbl}_{3}$ perovskites, as displacement damage seems to be significant. We therefore analyzed this specimen at a lower accelerating voltage of $80 \mathrm{kV}$. Figs $2 \mathrm{e}$ and $2 \mathrm{f}$ show TEM images of the same region of the $\mathrm{CH}_{3} \mathrm{NH}_{3} \mathrm{Pbl}_{3}$ perovskite before and after examination at $80 \mathrm{kV}$. The large and rapid damage to the material that occurred during the electron irradiation at $200 \mathrm{kV}$ is no longer observed at $80 \mathrm{kV}$, demonstrating that the accelerating voltage has to be chosen carefully to avoid degradation of $\mathrm{CH}_{3} \mathrm{NH}_{3} \mathrm{Pbl}_{3}$ perovskite film. In the literature, the use of accelerating voltages of $100 \mathrm{kV}[37,38,39]$ and $60 \mathrm{kV}[42]$ and short exposure times [43] has been reported for the study of $\mathrm{CH}_{3} \mathrm{NH}_{3} \mathrm{Pbl}_{3}$ perovskites. 

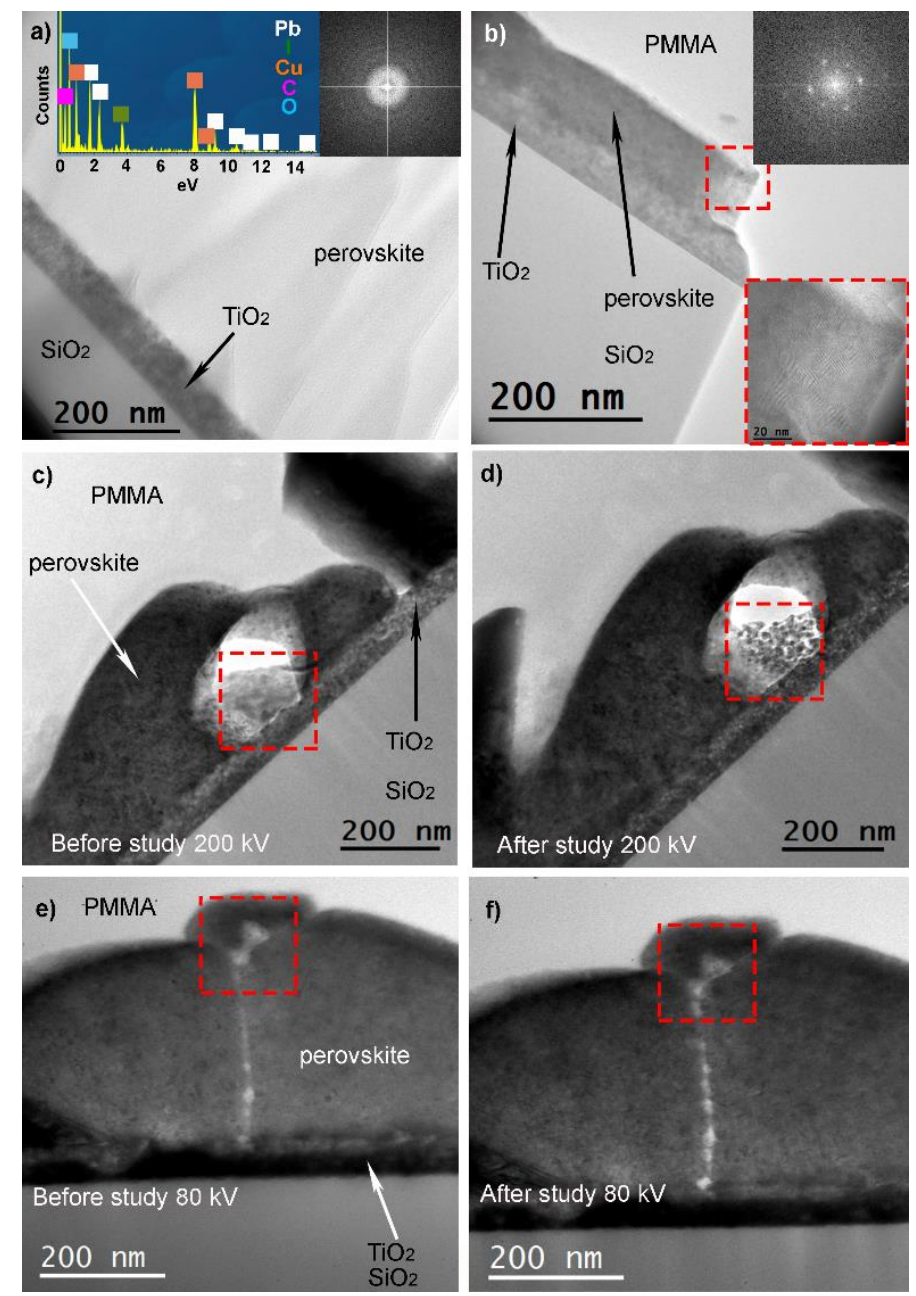

Fig. 2 a, b) TEM images of $\mathrm{SiO}_{2} / \mathrm{TiO}_{2} / \mathrm{CH}_{3} \mathrm{NH}_{3} \mathrm{Pbl}_{3}$ specimens prepared a) by conventional milling and b) by FIB milling; $c-f$ ) TEM images of the sample prepared by FIB milling recorded c, e) before and d, f) after electron irradiation at c, d) 200 and e, f) $80 \mathrm{kV}$.

Fig. 3a shows a scanning electron microscopy (SEM) image of a $\mathrm{CH}_{3} \mathrm{NH}_{3} \mathrm{Pbl}_{3}$ lamella, in which different layers of the sample structure can be observed, recorded in the FIB workstation after specimen preparation. EDX spectroscopy was used to identify the layers (see inset). The perovskite layer does not have a uniform thickness because the layers are formed from the crystallization of grains that grow independently with different orientations and sizes. It has been reported that the one step synthesis-deposition method that was used in the fabrication of the material is affected by an imbalance between nucleation and growth rates, leading to different morphologies of the perovskite layer [44]. A DMF intermediate was used during fabrication, as it has been reported to produce an enhancement [44] that contributes to control of the crystallization of the perovskite layer [45]. However, even after using the DMF intermediate, our results indicate that the layer thickness is not uniform. In order to investigate the initial steps of layer formation, a second sample, in which the concentration of the precursor in solution was four times lower, was analyzed. Fig. 3b shows an SEM image of the resulting structure, in which the perovskite has not crystallized in a uniform layer, but as islands of thickness $80-100 \mathrm{~nm}$. The layer shows irregular growth from the initial steps of material deposition. As shown in the regions marked by squares, the initial perovskite layer is not always flat, but contains some uneven regions, which will affect the geometry of the material when a full layer is grown. The analysis allows the adherence of the perovskite to the substrate, which is essential to obtain good performance of the solar cells $[44,45,46]$, to be assessed. A second 
inset to Fig. 3a contains an HRTEM image of the interface between the $\mathrm{TiO}_{2}$ and $\mathrm{CH}_{3} \mathrm{NH}_{3} \mathrm{Pbl}_{3}$. There is no gap between the materials, demonstrating good adhesion of the active layer to the $\mathrm{TiO}_{2}$. The PMMA layer shows perfect coverage of the semiconductor in Figs $3 a$ and $3 b$, suggesting that it can act as an effective protective layer for the perovskite against atmospheric conditions that could result in premature degradation.

HRTEM analysis of the perovskite layer was carried out to study the crystal structure and quality of the sample in more detail. Fig. 3c shows an HRTEM image of the $\mathrm{CH}_{3} \mathrm{NH}_{3} \mathrm{Pbl}_{3}$ layer in Fig. $3 \mathrm{a}$. The layer is formed from small crystallites, whose sizes range between 5 and $20 \mathrm{~nm}$. Some of the crystallites are faceted, as shown in the two insets to Fig. 3c. The presence of facets in the $\mathrm{CH}_{3} \mathrm{NH}_{3} \mathrm{Pbl}_{3}$ perovskite have been observed previously [49] and results from the minimization of total surface free energy according to thermodynamic theory $[48,49]$. FFTs of the HRTEM images were analyzed to identify the crystal structure of the $\mathrm{CH}_{3} \mathrm{NH}_{3} \mathrm{Pbl}_{3}$ perovskite. For comparative purposes, kinematic digital diffraction patterns (DDPs) of the three possible crystalline structures of $\mathrm{CH}_{3} \mathrm{NH}_{3} \mathrm{Pbl}_{3}$ (orthorhombic (Pnma), tetragonal $(14 / \mathrm{mcm})$ and cubic $(P m 3 m)$ ) were simulated using Eje $Z$ software [31]. Distances and angles were measured from the experimental FFTs automatically in Digital Micrograph using the script diftool, which provides better precision than manual measurements. Fig. $3 \mathrm{~d}$ shows an experimental FFT obtained from an HRTEM image of the specimen, alongside a calculated DDP for the tetragonal crystalline structure. There is a good agreement between the patterns. The angles and distances measured from the FFT were introduced into the software, which compares the measured values with all of the possibilities for the three crystal structures. This analysis is consistent with a tetragonal crystal structure of the analyzed perovskite. It was carried out in several regions of the perovskite layer, as well as in the sample with a reduced precursor concentration, showing the same result. The results of the analysis are consistent with the PL measurements, which also suggest a tetragonal crystal structure. Although some previous studies have reported that the tetragonal structure of $\mathrm{CH}_{3} \mathrm{NH}_{3} \mathrm{Pbl}_{3}$ forms at room temperature and the cubic phase forms at higher temperature $\left(>54^{\circ} \mathrm{C}\right)$ [52], others report that the two structures can coexist at room temperature [53]. The transition from a tetragonal to a cubic structure is accompanied by a slight distortion of $\mathrm{Pbl}_{6}$ octahedra about the $c$ axis [52]. The crystal structure of the perovskites is important to understand their optical properties, as it has an effect, for example, on their band gap, with a difference of $0.03 \mathrm{eV}$ reported between the band gaps of tetragonal and cubic $\mathrm{CH}_{3} \mathrm{NH}_{3} \mathrm{Pbl}_{3}$ [54].
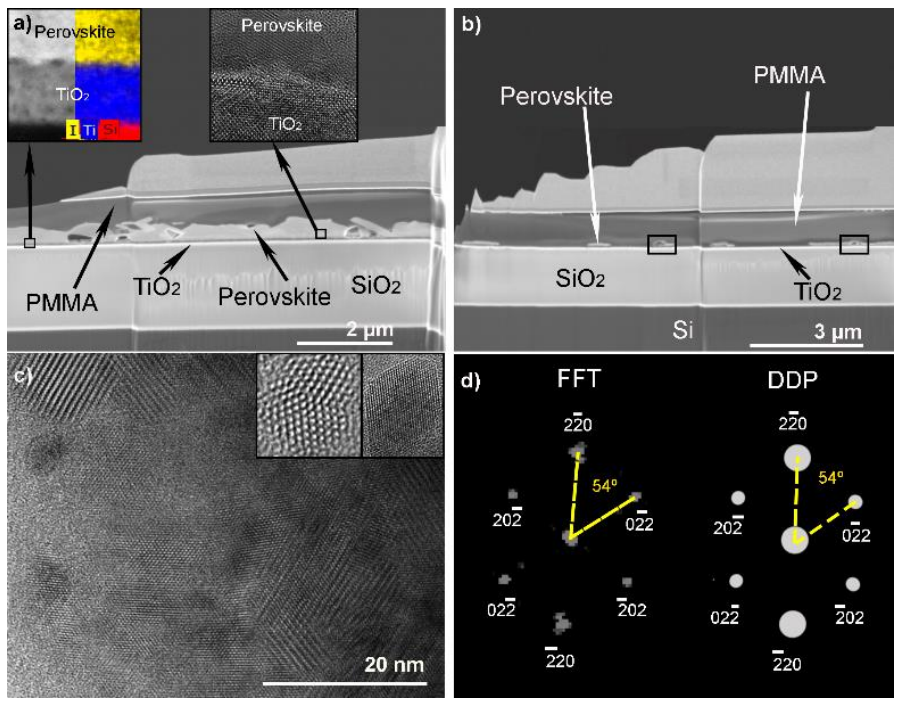

Fig. 3: SEM images of $\mathrm{CH}_{3} \mathrm{NH}_{3} \mathrm{Pbl}_{3}$ lamellae for a) $40 \%$ and b) $10 \%(\mathrm{w} / \mathrm{w})$ concentrations of the precursor samples; c) HRTEM image of the $\mathrm{CH}_{3} \mathrm{NH}_{3} \mathrm{Pbl}_{3}$ region, with the inset showing faceted 
particles; d) Experimental FFT shown alongside a calculated DDP for a tetragonal crystal structure.

Perovskite $\mathrm{CsPbBr}_{3}$ NPs were also analyzed. Fig. 4a shows a low magnification high-angle annular dark-field (HAADF) STEM image of $\mathrm{CsPbBr}_{3}$ NPs deposited on a Si substrate. The deposited perovskite particles are rectangular, with a size of $\sim 17 \pm 6 \mathrm{~nm}$. Unlike for the $\mathrm{CH}_{3} \mathrm{NH}_{3} \mathrm{Pbl}_{3}$ layers, the fabrication process involved two steps. First, the perovskite material was synthesized in a colloidal solution and deposited onto the substrate. The synthetized material in solution was analyzed by TEM before deposition onto the substrate. $\mathrm{CsPbBr}_{3} \mathrm{NPs}$ synthesized at room temperature have rectangular shapes, and similar dimensions [15]. The sizes and shapes of the $\mathrm{CsPbBr}_{3}$ particles are key to control the optical properties of the material [33], [55], [56], and can be tuned by modifying the solvent, ligand and reaction time [57]. We find that these characteristics of the $\mathrm{CsPBBr}_{3}$ particles are not modified after their deposition onto a solid substrate, which is encouraging for their integration into solid state devices. In the film, the particles are deposited close to each other. However, some gaps can be observed between them. Subsequent particles are deposited on the initial ones, but do not seem to fill the small gaps. The PMMA layer shows perfect coverage of the perovskite particles (see Fig. 4a), just as for the $\mathrm{CH}_{3} \mathrm{NH}_{3} \mathrm{Pbl}_{3}$ sample.

The NPs have crystalline structures, as can be observed in the inset to Fig. 4a. The crystal structure was studied using the procedure described above. In this case, the three possible structures of the $\mathrm{CsPbBr}_{3}$ perovskite are cubic $(P m-3 m)$, tetragonal $(P 4 / \mathrm{mbm})$ and orthorhombic $(P n m a)$. Fig. $4 \mathrm{~b}$ shows an FFT of the image in the inset to Fig. 4 a, alongside a calculated DDP for a cubic structure. Good agreement is observed, suggesting that the crystal structure of the perovskite material analyzed is cubic and consistent with the results obtained from the PL study. This cubic structure has been reported to be advantageous for $\mathrm{CsPbBr}_{3}$ perovskites for photovoltaic applications due to its optimal band gap of $2.4 \mathrm{eV}$ [58] in nanoparticle form. Other low temperature synthesis methods lead to yellow and non-luminescent nanocrystals, as a result of poor crystallinity or the formation of an orthorhombic crystal structure [59]. However, it has been reported that the cubic structure suffers a transformation to the orthorhombic structure when it is exposed to ambient conditions [60]. Several options have been considered to stabilize the cubic structure. For example, purification with methyl acetate (MeOAc) has proved to be a route to stabilize the cubic structure under ambient conditions for months [61]. The introduction of a layer of PMMA is also a potential solution, as it provides efficient coverage of the perovskite, as shown in the present work.

In order to study the compositional distribution in the perovskite layer, EDX analysis of the particles was carried out, as shown in Figs $4 \mathrm{c}$ and $4 \mathrm{~d}$. The EDX map shown in Fig. 4c confirms the expected uniform distribution of the elements. The slight increase in signal on the left side of the particle is thought to results from an increase in the thickness of the material in this region, as it is found for all of the elements. In Fig. $4 \mathrm{~d}$, although the distribution of $\mathrm{Br}$ and $\mathrm{Cs}$ is uniform, the distribution of $\mathrm{Pb}$ is inhomogeneous. $\mathrm{Pb}^{0}$ formation in halide perovskites under light illumination has been previously reported using XPS and XRD [62]. The EDX map shows a larger amount of $\mathrm{Pb}$ at the edges of the nanoparticle. An inset showing only the $\mathrm{Pb}$ distribution is included to show the enriched edges. Similar results were found in some other $\mathrm{CsPbBr}_{3}$ nanoparticles in this sample, although with a lower degree of segregation. Recent studies reported the degradation of hybrid and all-inorganic lead halide perovskites under electron beam irradiation in the TEM [26]. In particular, it was reported that $\mathrm{CsPbBr}_{3}$ particles undergo a radiolysis process that results in the desorption of $\mathrm{Br}$ atoms and the reduction of $\mathrm{Pb}^{2+}$ ions to $\mathrm{Pb}^{0}$ [26], which diffuse and aggregate to form non-epitaxial Pb crystals [26]. The damage was found 
to be particularly pronounced at the corners and edges of the perovskite layer, as there is a lower diffusion barrier for $\mathrm{Pb}^{0}$ in these regions [26]. Our results also point in this direction. The longer exposure times used for the acquisition of EDX maps in the electron microscope, in comparison to conventional imaging modes, results in the initial stages of material decomposition in some particles. This decomposition is more pronounced at the edges of the particles, as shown in Fig. 4d. It is also more likely in regions of reduced thickness. Care is therefore required in the study of perovskite materials using (S)TEM techniques, in order to avoid degradation of the material and to obtain reliable results.

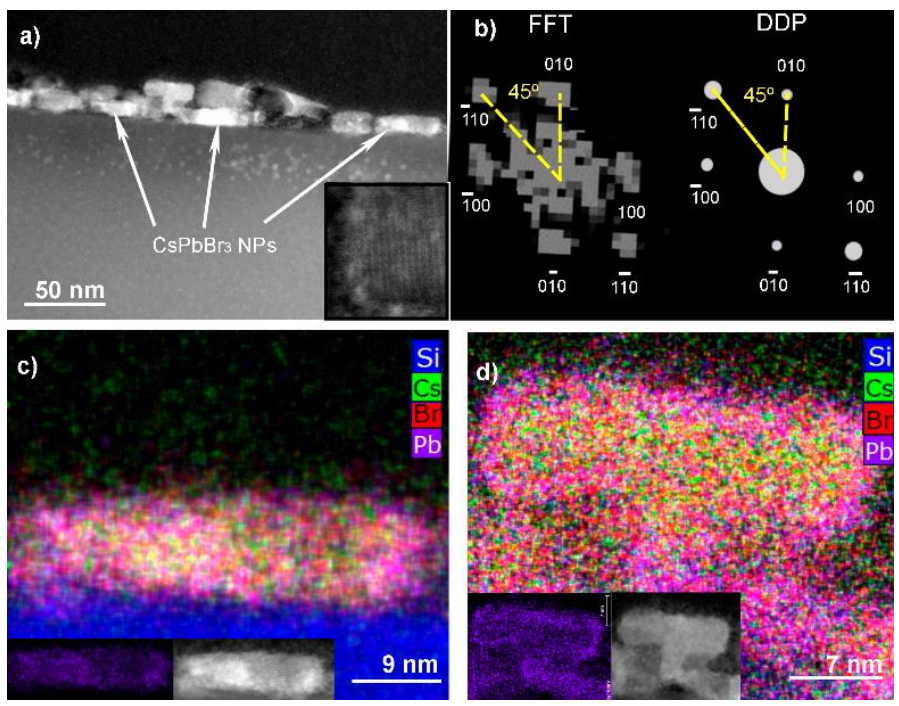

Fig. 4 a) Low magnification HAADF STEM image of $\mathrm{CsPbBr}_{3}$ nanoparticles deposited on $\mathrm{Si}$, with the inset showing a high-resolution HAADF STEM image of one of the $\mathrm{CsPBr}_{3}$ particles. b) Experimental FFT of the image in the inset to a) shown alongside a DDP calculated for a cubic structure. c, d) EDX maps of $\mathrm{CsPbBr}_{3}$ nanoparticles. Inset showing the $\mathrm{Pb}$ distributions and HAADF STEM images.

\section{Conclusions}

We have shown that specimen preparation using FIB milling instead of conventional techniques and the use of a low accelerating voltage of $80 \mathrm{kV}$ are required for (S)TEM analysis of $\mathrm{APbX}_{3}$ perovskites in order to avoid degradation of the material. Analysis of $\mathrm{CH}_{3} \mathrm{NH}_{3} \mathrm{Pbl}_{3}$ synthesized by a one step method shows that the active layer grows irregularly on a Si substrate from the initial steps of the crystallization process, with good adherence to a $\mathrm{TiO}_{2}$ layer. The crystal structure of the $\mathrm{CH}_{3} \mathrm{NH}_{3} \mathrm{Pbl}_{3}$ perovskite is shown to be tetragonal. A sharp absorption edge is localized at 750-760 nm, while an exciton absorption peak is centered at $750 \mathrm{~nm}$. $\mathrm{CsPbBr}_{3}$ nanoparticles deposited on a substrate are shown to have rectangular shapes similar to those before the deposition process. The crystal structure is cubic, which has an optimal band gap for photovoltaic applications. The addition of a PMMA layer provides efficient coverage of the active layer in both $\mathrm{APbX}_{3}$ perovskites. A PL spectrum shows a Gaussian shape centered at $517 \mathrm{~nm}$ with a FWHM of $21 \mathrm{~nm}$; a red Stokes shift can be explained by aggregation of the nanoparticles. Despite the low voltage used for (S)TEM analysis, long irradiation times result in segregation of $\mathrm{Pb}$ to the edges of the nanoparticles, which is the first step towards decomposition of the material. The analysis highlights the care that needed for (S)TEM measurements of both bulk and NP perovskite thin films.

\section{Acknowledgments}


This work was supported by the Spanish MINECO (projects TEC2014-53727-C2-1-R, -2-R and TEC2017-86102-C2-2-R) and Junta de Andalucía (PAI research group TEP-946). The research leading to these results has received co-funding from the European Union. B.C.H. is grateful for the support of the National Council of Technological and Scientific Development (CNPq), Brazil, through the Science without Borders program.

[1] C.R. Kalaiselvi, N. Muthukumarasamy, D. Velauthapillai, M. Kang, T.S. Senthil, Importance of halide perovskites for next generation solar cells - A review, Mater. Lett. 219 (2018) 198-200. doi:10.1016/j.matlet.2018.02.089.

[2] B.R. Sutherland, E.H. Sargent, Perovskite photonic sources, Nat. Photonics. 10 (2016) 295-302. doi:10.1038/nphoton.2016.62.

[3] S. de Wolf, J. Holovsky, S.-J. Moon, P. Löper, B. Niesen, M. Ledinsky, F. Haug, J. Yum, C. Ballif, Organometallic Halide Perovskites: Sharp Optical Absorption Edge and Its Relation to Photovoltaic Performance, J. Phys. Chem. C. 5 (2014) 1035-139. doi:10.1021/jz500279b.

[4] H.S. Kim, C.R. Lee, J.H. Im, K.B. Lee, T. Moehl, A. Marchioro, S.J. Moon, R. HumphryBaker, J.H. Yum, J.E. Moser, M. Grätzel, N.G. Park, Lead iodide perovskite sensitized allsolid-state submicron thin film mesoscopic solar cell with efficiency exceeding $9 \%$, Sci. Rep. 2 (2012) 1-7. doi:10.1038/srep00591.

[5] Michael M. Lee, J. Teuscher, T. Miyasaka, T.N. Murakami, H.J. Snaith, Efficient Hybrid Solar Cells Based on Meso-Superstructured Organometal Halide Perovskites, 338 (2012) 1209-1214.

[6] https://www.nrel.gov/pv/assets/images/efficiency-chart.png, (n.d.).

[7] I. Suárez, E.J. Juárez-Pérez, J. Bisquert, I. Mora-Serõ, J.P. Martínez-Pastor, Polymer/Perovskite Amplifying Waveguides for Active Hybrid Silicon Photonics, Adv. Mater. 27 (2015) 6157-6162. doi:10.1002/adma.201503245.

[8] G.E. Eperon, S.N. Habisreutinger, T. Leijtens, B.J. Bruijnaers, J.J. van Franeker, D.W. deQuilettes, S. Pathak, R.J. Sutton, G. Grancini, D.S. Ginger, The importance of moisture in hybrid lead halide perovskite thin film fabrication, ACS Nano. 9 (2015) 851-9380.

[9] J. Troughton, K. Hooper, T.M. Watson, Humidity resistant fabrication of $\mathrm{CH} 3 \mathrm{NH} 3 \mathrm{Pbl} 3$ perovskite solar cells and modules, Nano Energy. 39 (2017) 60-68. doi:10.1016/j.nanoen.2017.06.039.

[10] M. Kulbak, S. Gupta, N. Kedem, I. Levine, T. Bendikov, G. Hodes, D. Cahen, Cesium Enhances Long-Term Stability of Lead Bromide Perovskite-Based Solar Cells, J. Phys. Chem. Lett. 7 (2016) 167-172. doi:10.1021/acs.jpclett.5b02597.

[11] F. Fabregat-Santiago, M. Kulbak, A. Zohar, M. Vallés-Pelarda, G. Hodes, D. Cahen, I. Mora-Seró, Deleterious Effect of Negative Capacitance on the Performance of Halide Perovskite Solar Cells, ACS Energy Lett. 2 (2017) 2007-2013. doi:10.1021/acsenergylett.7b00542.

[12] A. Swarnkar, R. Chulliyil, V.K. Ravi, M. Irfanullah, A. Chowdhury, A. Nag, Colloidal CsPbBr ${ }_{3}$ Perovskite Nanocrystals: Luminescence beyond Traditional Quantum Dots, Angew. Chemie. 127 (2015) 15644-15648. doi:10.1002/ange.201508276.

[13] X. Li, Y. Wu, S. Zhang, B. Cai, Y. Gu, J. Song, H. Zeng, CsPbX3Quantum Dots for Lighting and Displays: Roomerature Synthesis, Photoluminescence Superiorities, Underlying Origins and White Light-Emitting Diodes, Adv. Funct. Mater. 26 (2016) 2435-2445. doi:10.1002/adfm.201600109.

[14] C.C. Stoumpos, C.D. Malliakas, J.A. Peters, Z. Liu, M. Sebastian, J. Im, T.C. Chasapis, A.C. 
Wibowo, D.Y. Chung, A.J. Freeman, B.W. Wessels, M.G. Kanatzidis, Crystal Growth of the Perovskite Semiconductor $\mathrm{CsPbBr} 3$ : A New Material for High-Energy Radiation Detection, Cryst. Growth Des. 13 (2018) 2722-2727. doi:10.1016/j.matlet.2018.02.089.

[15] B. ClasenHames, R. SánchezSánchez, A. Fakharuddin, I. Mora-Seró, A Comparative Study of Light-Emitting Diodes Based on All-Inorganic Perovskite Nanoparticles ( $\mathrm{CsPbBr} 3$ ) Synthesized at Room Temperature and by a Hot-Injection Method, Chempluschem. (2018) 1-7. doi:10.1002/cplu.201800014.

[16] J. Ding, S. Du, Z. Zuo, Y. Zhao, H. Cui, X. Zhan, High Detectivity and Rapid Response in Perovskite CsPbBr3Single-Crystal Photodetector, J. Phys. Chem. C. 121 (2017) 49174923. doi:10.1021/acs.jpcc.7b01171.

[17] J.B. Hoffman, G. Zaiats, I. Wappes, P. V. Kamat, CsPbBr3Solar Cells: Controlled Film Growth through Layer-by-Layer Quantum Dot Deposition, Chem. Mater. 29 (2017) 9767-9774. doi:10.1021/acs.chemmater.7b03751.

[18] L. Wagner, L.E. Mundt, G. Mathiazhagan, M. Mundus, M.C. Schubert, S. Mastroianni, U. Würfel, A. Hinsch, S.W. Glunz, Distinguishing crystallization stages and their influence on quantum efficiency during perovskite solar cell formation in real-time, Sci. Rep. 7 (2017) 1-6. doi:10.1038/s41598-017-13855-6.

[19] D. Ghosh, M.Y. Ali, D.K. Chaudhary, S. Bhattacharyya, Dependence of halide composition on the stability of highly efficient all-inorganic cesium lead halide perovskite quantum dot solar cells, Sol. Energy Mater. Sol. Cells. 185 (2018) 28-35. doi:10.1016/j.solmat.2018.05.002.

[20] H. Uratani, K. Yamashita, Charge Carrier Trapping at Surface Defects of Perovskite Solar Cell Absorbers: A First-Principles Study, J. Phys. Chem. Lett. 8 (2017) 742-746. doi:10.1021/acs.jpclett.7b00055.

[21] Y. Yang, M. Yang, D.T. Moore, Y. Yan, E.M. Miller, K. Zhu, M.C. Beard, Top and bottom surfaces limit carrier lifetime in lead iodide perovskite films, Nat. Energy. 2 (2017) 1-7. doi:10.1038/nenergy.2016.207.

[22] W.S. Yang, J.H. Noh, N.J. Jeon, Y.C. Kim, S. Ryu, J. Seo, S.I. Seok, High-Performance Photovoltaic Perovskite Layers Fabricated through Intramolecular Exchange, Sci. (80-. ). 348 (2015) 1234-1237. doi:10/f7fzcf.

[23] A. Sharenko, M.F. Toney, Relationships between Lead Halide Perovskite Thin-Film Fabrication, Morphology, and Performance in Solar Cells, J. Am. Chem. Soc. 138 (2016) 463-470. doi:10.1021/jacs.5b10723.

[24] D. Meggiolaro, S. Motti, E. Mosconi, A. barker, J. Ball, C.A.R. Perini, F. Deschler, A. Petrozza, F. De Angelis, lodine chemistry determines the defect tolerance of lead-halide perovskites, Energy Environ. Sci. 11 (2018) 702-713. doi:10.1039/C8EE00124C.

[25] A. Vassilakopoulou, D. Papadatos, I. Koutselas, Light emitting diodes based on blends of quasi-2D lead halide perovskites stabilized within mesoporous silica matrix, Microporous Mesoporous Mater. 249 (2017) 165-175. doi:10.1016/j.micromeso.2017.05.001.

[26] Z. Dang, J. Shamsi, F. Palazon, M. Imran, Q.A. Akkerman, S. Park, G. Bertoni, M. Prato, R. Brescia, L. Manna, In Situ Transmission Electron Microscopy Study of Electron BeamInduced Transformations in Colloidal Cesium Lead Halide Perovskite Nanocrystals, ACS Nano. 11 (2017) 2124-2132. doi:10.1021/acsnano.6b08324.

[27] M. Xiao, F. Huang, W. Huang, Y. Dkhissi, Y. Zhu, J. Etheridge, A. Gray-Weale, U. Bach, Y.B. Cheng, L. Spiccia, A Fast Deposition-Crystallization Procedure for Highly Efficient Lead(supporting), Angew. Chemie. 126 (2014) 10056-10061. doi:10.1002/ange.201405334. 
[28] Q. Jeangros, M. Duchamp, J. Werner, M. Kruth, R.E. Dunin-Borkowski, B. Niesen, C. Ballif, A. Hessler-Wyser, In Situ TEM Analysis of Organic-Inorganic Metal-Halide Perovskite Solar Cells under Electrical Bias, Nano Lett. 16 (2016) 7013-7018. doi:10.1021/acs.nanolett.6b03158.

[29] M. Zhang, H. Li, Q. Jing, Z. Lu, P. Wang, Atomic Characterization of Byproduct Nanoparticles on Cesium Lead Halide Nanocrystals Using High-Resolution Scanning Transmission Electron Microscopy, Crystals. 8 (2017) 2. doi:10.3390/cryst8010002.

[30] I. Suárez, A. Larrue, P.J. Rodríguez-Cantó, G. Almuneau, R. Abargues, V.S. Chirvony, J.P. Martínez-Pastor, Efficient excitation of photoluminescence in a two-dimensional waveguide consisting of a quantum dot-polymer sandwich-type structure, Opt. Lett. 39 (2014) 4962. doi:10.1364/OL.39.004962.

[31] J.A. Pérez-Omil, Eje Z, (2016).

[32] L.M. Herz, Charge-Carrier Dynamics in Organic-Inorganic Metal Halide Perovskites, Annu. Rev. Phys. Chem. 67 (2016) 65-89. doi:10.1146/annurev-physchem-040215112222.

[33] L. Protesescu, S. Yakunin, M.I. Bodnarchuk, F. Krieg, R. Caputo, C.H. Hendon, R.X. Yang, A. Walsh, M. V. Kovalenko, Nanocrystals of Cesium Lead Halide Perovskites ( $\mathrm{CsPbX}<\inf >3</ \mathrm{inf}>, \mathrm{X}=\mathrm{Cl}, \mathrm{Br}$, and $\mathrm{I})$ : Novel Optoelectronic Materials Showing Bright Emission with Wide Color Gamut, Nano Lett. 15 (2015) 3692-3696. doi:10.1021/nl5048779.

[34] X. Tang, Z. Hu, W. Chen, X. Xing, Z. Zang, W. Hu, J. Qiu, J. Du, Y. Leng, X. Jiang, L. Mai, Room temperature single-photon emission and lasing for all-inorganic colloidal perovskite quantum dots, Nano Energy. 28 (2016) 462-468. doi:10.1016/j.nanoen.2016.08.062.

[35] S.N. Raja, Y. Bekenstein, M.A. Koc, S. Fischer, D. Zhang, L. Lin, R.O. Ritchie, P. Yang, A.P. Alivisatos, Encapsulation of Perovskite Nanocrystals into Macroscale Polymer Matrices: Enhanced Stability and Polarization, ACS Appl. Mater. Interfaces. 8 (2016) 3552335533. doi:10.1021/acsami.6b09443.

[36] R.F. Egerton, P. Li, M. Malac, Radiation damage in the TEM and SEM, 35 (2004) 399409. doi:10.1016/j.micron.2004.02.003.

[37] D.B. Williams, C.B. Carter, Transmission Electron Microscopy, 2009.

[38] Pepinsky, Vedam, Hoshino, Okaya, Radiation Damage in Ge and Si detected by carrier lifetime changes: damage thresholds, Phys. Rev. 111 (1958) 432-439.

[39] D. Zhong, B. Cai, X. Wang, Z. Yang, Y. Xing, S. Miao, W.H. Zhang, C. Li, Synthesis of oriented TiO2nanocones with fast charge transfer for perovskite solar cells, Nano Energy. 11 (2015) 409-418. doi:10.1016/j.nanoen.2014.11.014.

[40] S. Yang, Y.C. Zheng, Y. Hou, X. Chen, Y. Chen, Y. Wang, H. Zhao, H.G. Yang, Formation mechanism of freestanding $\mathrm{CH} 3 \mathrm{NH} 3 \mathrm{~Pb}$ I 3 functional crystals: In situ transformation vs dissolution-crystallization, Chem. Mater. 26 (2014) 6705-6710. doi:10.1021/cm5028817.

[41] B. Yang, O. Dyck, W. Ming, M.-H. Du, S. Das, C.M. Rouleau, G. Duscher, D.B. Geohegan, K. Xiao, Observation of Nanoscale Morphological and Structural Degradation in Perovskite Solar Cells by in Situ TEM, ACS Appl. Mater. Interfaces. 8 (2016) 3233332340. doi:10.1021/acsami.6b11341.

[42] S.-T. Ha, R. Su, J. Xing, Q. Zhang, Q. Xiong, Metal halide perovskite nanomaterials: synthesis and applications, Chem. Sci. 8 (2017) 2522-2536. doi:10.1039/C6SC04474C.

[43] Y. Zhou, A.L. Vasiliev, W. Wu, M. Yang, S. Pang, K. Zhu, N.P. Padture, Crystal 
morphologies of organolead trihalide in mesoscopic/planar perovskite solar cells, J. Phys. Chem. Lett. 6 (2015) 2292-2297. doi:10.1021/acs.jpclett.5b00981.

[44] Z. Yao, T.W. Jones, M. Grigore, N.W. Duffy, K.F. Anderson, R.B. Dunbar, K. Feron, F. Hao, H. Lin, G.J. Wilson, Tunable Crystallization and Nucleation of Planar CH3NH3Pbl3through Solvent-Modified Interdiffusion, ACS Appl. Mater. Interfaces. 10 (2018) 14673-14683. doi:10.1021/acsami.8b00887.

[45] W. Li, J. Fan, J. Li, Y. Mai, L. Wang, Controllable grain morphology of perovskite absorber film by molecular self-assembly toward efficient solar cell exceeding $17 \%, \mathrm{~J}$. Am. Chem. Soc. 137 (2015) 10399-10405. doi:10.1021/jacs.5b06444.

[46] J. Shao, S. Yang, Y. Liu, Efficient Bulk Heterojunction CH3NH3Pbl3-TiO2 Solar Cells with TiO2 Nanoparticles at Grain Boundaries of Perovskite by Multi-Cycle-Coating Strategy, ACS Appl. Mater. Interfaces. 9 (2017) 16202-16214. doi:10.1021/acsami.7b02323.

[47] F. Han, J. Luo, Z. Wan, X. Liu, C. Jia, Dissolution-recrystallization method for high efficiency perovskite solar cells, Appl. Surf. Sci. 408 (2017) 34-37. doi:10.1016/j.apsusc.2017.02.150.

[48] Y.Q. Wang, S. Bin Xu, J.G. Deng, L.Z. Gao, Enhancing the efficiency of planar heterojunction perovskite solar cells via interfacial engineering with 3-aminopropyl trimethoxy silane hydrolysate, R. Soc. Open Sci. 4 (2017). doi:10.1098/rsos.170980.

[49] Y. Chen, S. Yang, X. Chen, Y.C. Zheng, Y. Hou, Y.H. Li, H.D. Zeng, H.G. Yang, Direct insight into crystallization and stability of hybrid perovskite $\mathrm{CH}_{3} \mathrm{NH}_{3} \mathrm{Pbl}_{3}$ via solvothermal synthesis, J. Mater. Chem. A. 3 (2015) 15854-15857. doi:10.1039/C5TA03616J.

[50] S. Miracle-Sole, Surface tension, step free energy, and facets in the equilibrium crystal, J. Stat. Phys. 79 (1995) 183-214. doi:10.1007/BF02179386.

[51] X. Huang, T.R. Paudel, P.A. Dowben, S. Dong, E.Y. Tsymbal, Electronic structure and stability of the CH3NH3PbBr3 (001) Surface, Phys. Rev. B. 94 (2016) 195309. doi:10.1103/PhysRevB.94.195309.

[52] A. Poglitsch, D. Weber, Dynamic disorder in methylammoniumtrihalogenoplumbates (II) observed by millimeter-wave spectroscopy, J. Chem. Phys. 87 (1987) 6373-6378. doi:10.1063/1.453467.

[53] T.W. Kim, S. Uchida, T. Matsushita, L. Cojocaru, R. Jono, K. Kimura, D. Matsubara, M. Shirai, K. Ito, H. Matsumoto, T. Kondo, H. Segawa, Self-Organized Superlattice and Phase Coexistence inside Thin Film Organometal Halide Perovskite, Adv. Mater. 30 (2018) 1-8. doi:10.1002/adma.201705230.

[54] S.X. Tao, X. Cao, P.A. Bobbert, Accurate and efficient band gap predictions of metal halide perovskites using the DFT-1/2 method: GW accuracy with DFT expense, Sci. Rep. 7 (2017) 1-39. doi:10.1038/s41598-017-14435-4.

[55] A. Shinde, R. Gahlaut, S. Mahamuni, Low-Temperature Photoluminescence Studies of CsPbBr3Quantum Dots, J. Phys. Chem. C. 121 (2017) 14872-14878. doi:10.1021/acs.jpcc.7b02982.

[56] S. Ye, M. Zhao, J. Song, J. Qu, Controllable emission bands and morphologies of highquality CsPbX3perovskite nanocrystals prepared in octane, Nano Res. (2018) 1-10. doi:10.1007/s12274-018-2046-4.

[57] S. Seth, A. Samanta, A facile methodology for engineering the morphology of CsPbX3perovskite nanocrystals under ambient condition, Sci. Rep. 6 (2016) 1-7. doi:10.1038/srep37693.

[58] E.M.L.D. De Jong, G. Yamashita, L. Gomez, M. Ashida, Y. Fujiwara, T. Gregorkiewicz, Multiexciton lifetime in all-inorganic CsPbBr3perovskite nanocrystals, J. Phys. Chem. C. 
121 (2017) 1941-1947. doi:10.1021/acs.jpcc.6b10551.

[59] R. Aceves, V. Babin, M. Barboza Flores, P. Fabeni, M. Nikl, K. Nitsch, G.P. Pazzi, R. Perez Salas, S. Zazubovich, Luminescence of $\mathrm{CsPbCl}_{3}$-like Quantum Dots in $\mathrm{CsCl}: \mathrm{Pb}$ Crystals, Phys. Status Solidi. 225 (2001) 247-255. doi:10.1002/(SICI)15213951(200105)225:1<247::AID-PSSB247>3.0.CO;2-L.

[60] R.E. Beal, D.J. Slotcavage, T. Leijtens, A.R. Bowring, R.A. Belisle, W.H. Nguyen, G.F. Burkhard, E.T. Hoke, M.D. McGehee, Cesium Lead Halide Perovskites with Improved Stability for Tandem Solar Cells, J. Phys. Chem. Lett. 7 (2016) 746-751. doi:10.1021/acs.jpclett.6b00002.

[61] A. Swarnkar, A.R. Marshall, E.M. Sanehira, B.D. Chernomordik, D.T. Moore, J.A. Christians, T. Chakrabarti, J.M. Luther, Quantum dot-induced phase stabilization of $\alpha$ CsPbl3perovskite for high-efficiency photovoltaics, Science (80-. ). 354 (2016) 92-95. doi:10.1126/science.aag2700.

[62] E.J. Juarez-Perez, L.K. Ono, M. Maeda, Y. Jiang, Z. Hawash, Y. Qi, Photodecomposition and thermal decomposition in methylammonium halide lead perovskites and inferred design principles to increase photovoltaic device stability, J. Mater. Chem. A. 6 (2018) 9604-9612. doi:10.1039/c8ta03501f. 